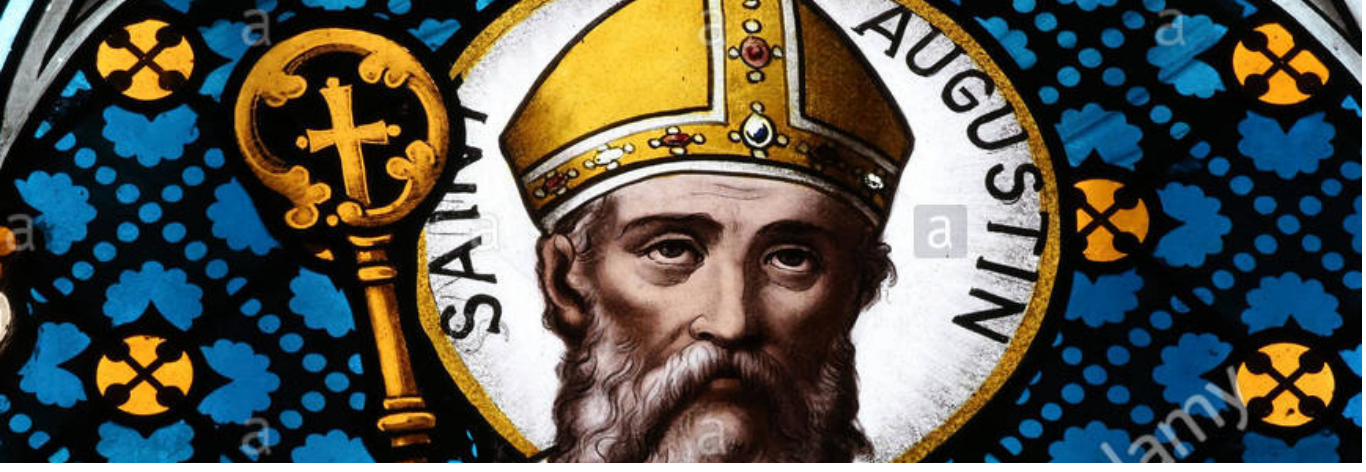

\section{Inquietud y deseo. El legado de san Agustín en la filosofía contemporánea}

Restlessness and desire. Saint Augustine's legacy in contemporary philosophy

\section{Resumen}

Este trabajo tiene el fin, principalmente histórico, de mostrar la influencia del pensamiento agustiniano en algunos movimientos importantes de la filosofía de los siglos XX y XXI. Está dividido en tres partes. En la primera busco esclarecer los modos y perspectivas desde la cuales puede hacerse un trabajo de rastreo histórico. En la segunda desarrollo las ideas de "inquietud" y de "deseo", yendo a las fuentes primarias en Agustín desde una aproximación fenomenológica. En la tercera parte, explico el modo como ambos temas aparecen en tres líneas de pensamiento específicas: la antropología filosófica, la filosofía de la religión y la fenomenología.

\section{Palabras clave}

Agustín de Hipona, Deseo, Fenomenología, Inquietud, Religión.

\begin{abstract}
. The aim of this work is fundamentally historical: to show the influence of the augustinian philosophy in some of the most important philosophical movements of the XX and XXI centuries. It is divided in three parts. In the first one, I try to explain the modes and perspectives in which such a historical task can be done. In the second part I develop the ideas of "unease" and "desire" going to the main sources in Augustine from a phenomenological approach. In the third part, I try to explain the way in which both themes appear in three specific lines of thinking: Philosophical Anthropology, Philosophy of Religion and Phenomenology.
\end{abstract}

\section{Keywords}

Augustine of Hippo, Desire, Phenomenology, Religion, Unease.
DIEGO IGNACIO ROSALES MEANA Instituto Tecnológico de Monterrey y Conacyt,

México

Doctor en filosofía por la Universidad Pontificia Comillas de Madrid. Es miembro del Sistema Nacional de Investigadores del Conacyt (Nivel 1) y profesor en el departamento de Humanidades del Instituto Tecnológico de Monterrey. Es miembro del Círculo Latinoamericano de Fenomenología y miembro Correspondant de la Plataforma Alpha (Archivos Michel Henry) de la Universidad Católica de Lovaina. Entre sus publicaciones más recientes se encuentran los artículos: "Mínima fenomenología de la religión en Agustín de Hipona", "Hablar en silencio. Cuatro navegaciones", "Metafísica del cuerpo y de la historia en Charles Péguy" y el libro, de próxima aparición en Madrid: Antropología del deseo. La existencia personal en Agustín de Hipona (2020).

\section{ORCID 曲}

Recepción de artículo: 10-5-2019

Aceptación del artículo: 20-4-2020

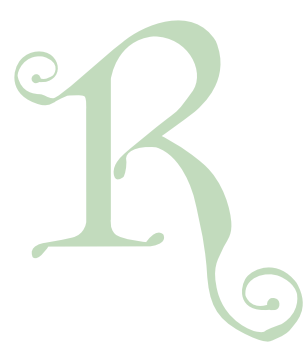




\section{INTRODUCCIÓN: LOS MODOS DE APROXIMACIÓN}

Difícilmente puede exagerarse la importancia de san Agustín para la historia de la filosofía. Pensador de transición histórica, Agustín sintentizó la filosofía helenística con el cristianismo y generó las categorías metafísicas sobre las que se construiría el castillo de la filosofía medieval. Es verdad que, si bien la Modernidad implicó una secularización filosófica y, en ese sentido muy amplio, un cierto abandono de la cosmovisión agustiniana, no es ningún secreto que las aportaciones más importantes de Descartes resultan incomprensibles si no van acompañadas de una lectura atenta del tratado De trinitate. Y no solamente Descartes, sino que Lutero, san Ignacio, Pascal y Montaigne, cuatro padres fundadores del mundo moderno, son también deudores del pensamiento agustiniano en un sentido mucho más que central.

Pensar la filosofía de Agustín en relación con la filosofía contemporánea no es una tarea fácil. Implica desentrañar los hilos sobre los que se ha tejido la filosofía en el siglo XX y detectar cuáles de ellos son propiamente de tradición y ralea agustiniana. Una manera de hacer esto es simplemente notar quiénes de los filósofos de los años 1900 hacia acá han citado, nombrado o utilizado a Agustín para la construcción de su propio pensamiento en un sentido muy general. En ese sentido, que es el más superficial, cabe mencionar nombres como Ludwig Wittgenstein, Edmund Husserl, Karl Jaspers, Hannah Arendt, Gadamer y Ricœur, Heidegger e incluso los posmodernos Lyotard y Derrida. Todos estos grandes han hecho alguna referencia a Agustín en algún lugar importante de su obra. Este trabajo de rastreo a través de citas tiene un interés principalmente historiográfico. Ayuda a comprender las fuentes de muchos de los filósofos más importantes en el siglo XX. Un trabajo así fue publicado por el profesor Jean-François Petit hace solo 5 años bajo el título Saint Augustin. Notre contemporain. Lectures XXe siècle en la editorial Bayard de Paris ${ }^{1}$. El libro recoge, a través de capítulos monográficos, la relación de san Agustín con diversos filósofos del XX; además de los que he mencionado, incluye la exposición de algunos otros como Blondel, Camus, Mounier o Marion. A todo esto hay que sumar, sin lugar a dudas, los trabajos de importantes filósofos que durante el siglo XX -y algunos otros ya entrado el XXI- han buscado sistematizar el pensamiento agustiniano, o bien, ofrecer una visión de conjunto de su obra a partir de su propio sistema filosófico Cabe aquí nombrar los trabajos de Gilson ${ }^{2}$, Sciacca ${ }^{3}$, Marion $^{4}$ o Williams 5 ; trabajos a los que podría sumarse, por ejemplo, la extraordinaria biografía de Peter Brown ${ }^{6}$

Hay otra manera, sin embargo, según la cual acometer una tarea similar. Una que no tenga un énfasis historiográfico sino uno filosófico propiamente dicho. Se trata de detectar la presencia de Agustín en el método y en los contenidos mismos de la estructura filosófica de algunas de las líneas de pensamiento más importantes hoy en día. Esto es lo que intentaré hacer en este artículo a partir de las nociones agustinianas de "inquietud" y "deseo" tal como están presentes y formuladas en tres ámbitos filosóficos particulares del siglo XX: la filosofía de la religión, la fenomenología y la filosofía de la existencia, así como de los cruces que se han dado entre estas tres líneas de pensamiento.

El ya clásico libro Lo Santo. Lo racional y lo irracional en la idea de Dios ${ }^{7}$ de Rudolf Otto se ha convertido en un clásido dentro de lo que hoy se conoce como "fenomenología de la religión». La tarea central de esta disciplina o de este método consiste en la descripción comprensiva de los rasgos que componen la estructura del fenómeno religioso en general. Este texto fungió como la base para futuras elaboraciones sobre el mismo problema, como lo hicieron Mircea Eliade en Lo sagrado y lo santo ${ }^{8}$, Max Scheler en De lo eterno en el hombre ${ }^{9}$ o Juan Martín Velasco en su monumental Introducción a la fenomenología de la religión ${ }^{10}$, por mencionar tres modos diferentes de «fenomenologías» de la religión. A pesar de sus diferencias, todas se reconocen en muy buena medida deudoras de los trabajos de Otto y de sus formulaciones, en especial de la descripción de «lo numinoso» como M ysterium tremendum et fascinans. Tanto Scheler como Eliade y Velasco asumen esta definición de «lo Santo» o del «Misterio» como la referencia ineludible desde la cual parten y con la cual dialogan.

Una pregunta no poco importante, en este contexto, es el correlato experiencial o vivencial por el que se accede a lo numinoso, al Mysterium. Me refiero ya no solamente a la exploración de aquello que pueda ser la realidad del Misterio en sí misma, sino a la experiencia subjetiva por la que el hombre entra en relación con esa realidad tremenda y fascinante. Esta vivencia, que desde Schleiermacher ${ }^{11}$ está asociada a un cierto sentimiento, a una cierta vivencia afectiva, exige ser comprendida si es que queremos dilucidar la esencia del fenómeno religioso.

Desde mi punto de vista, la línea de análisis más interesante para la comprensión de esta vivencia religiosa está en el examen de lo que ha sido llamado "vía de la interioridad», y que tiene su comienzo formal precisamente con Agustín de Hipona. Con antecedentes claros en Plotino y en el neoplatonismo en general, esta vía continúa en la Edad Media a través de Gregorio Magno y hasta las escuelas monásticas con san Bernardo, san Buenaventura o Ricardo de san Víctor. Y de aquí, nuevamente nos encontramos con algunos nombres modernos ya mencionados, como Pascal, Schelling, Kierkegaard y Blondel. En esta línea de pensamiento, una de las más interesantes fórmulas de la vía de la interioridad es la fecundísima fenomenología fundada por Edmund Husserl y algunas de sus "herejías", que encuentran una raíz profundamente agustiniana, como la línea desarrollada por Jean-Luc

\footnotetext{
1. Petit 2015.

2. Gilson 1929.

3. Sciacca 1949.

4. Marion 2008.

5. Williams 2016

6. Brown 2000.

7. Otto 1917.

8. Eliade 1956.

9. Scheler 1921.

10. Velasco 1999, 2006.

11. Schleiermacher 1830
} 
Marion ${ }^{12}$, Michel Henry ${ }^{13}$, Jean-Louis Chrétien ${ }^{14}$ y JeanYves Lacoste ${ }^{15}$, quienes hacen fenomenología en diálogo también con la filosofía existencial de Martin Heidegger. Todos ellos han sido calificados, despectivamente, como "el giro teológico de la fenomenología", por Dominique Janicaud ${ }^{16}$. Aunque pudo haber razón en algunas de las críticas emitidas por Janicaud, dicho calificativo no hizo sino exhibir y publicitar la necesidad que había en filosofía de que ingresaran en ella temas anteriormente relegados por un positivismo, jacobinsimo o cientificismo exacerbados.

Esta vía de la interioridad encuentra uno de sus orígenes centrales en la célebre fórmula agustiniana de Confesiones III, que describe el misterio de Dios como interior intimo meo et superior summo meo, como la realidad más honda que habita mi propia intimidad y también como la realidad más grande y sublime que comparece ante mí. En esta sucinta expresión, que en español puede decirse: «más dentro que mi intimidad más honda y más grande que lo más perfecto mío», puede encontrarse lo que permaneció por la travesía histórica que a grandes rasgos he delineado y que culmina con la filosofía de la vida de Michel Henry, que privilegia la experiencia de la intimidad en la "autoafección", vía por la que se tiene acceso a una subjetividad Absoluta, que es la Vida en sentido propio, y que Henry no duda en identificar con la presencia misma del Misterio en la carne ${ }^{17}$.

\section{INQUIETUD Y DESEO EN AGUSTÍN}

Este leitmotiv agustiniano funge como una de las fuentes más relevantes de la que abrevan todas las filosofías de la religión que conciben aquello que acontece en la experiencia que tiene el hombre de sí, como uno de los anclajes centrales del fenómeno religioso. Pero hay que señalar que el avance propiamente agustiniano se pone de relieve cuando se conjunta este famoso motto con el incipit de las Confesiones, ese poderoso texto que puede leerse como un programa filosófico que busca describir las condiciones sobre las cuales se cifra la existencia humana en el mundo, detonando lo que podríamos llamar una "fenomenología de la existencia personal". Cito a continuación el fragmento al que me refiero:

Grande eres, Señor, y laudable sobremanera; tu poder grande y tu sabiduría no tiene número. ¿Y pretende alabarte el hombre, pequeña parte de tu creación, justamente el hombre, rodeado de su mortalidad, del testimonio de su pecado y del testimonio de que resistes a los soberbios? Con todo, quiere alabarte ese hombre, pequeña parte de tu creación. Tú mismo le excitas a ello, haciendo que se deleite en la alabanza, porque nos has hecho para ti y nues- tro corazón está inquieto hasta que descanse en ti ${ }^{18}$.

El final del pasaje citado: "inquietum est cor nostrum donec requiescat in te", que suele ser leído más como una pía oración que como una proposición filosófica, es el cimiento de una fenomenología de la facticidad mucho más fundamental que la de Heidegger, pues en ella quedan cifrados los contenidos básicos de la fenomenología de la existencia personal: el destino del hombre se sustrae al mundo de modo que su relación con él estará siempre atravesada por un marcador de insatisfacción. Este destino escatológico del deseo humano, cuya inquietud fundamental sólo puede ser colmada con una realidad fuera del tiempo, marca de manera definitiva la relación del hombre con el espacio y con el tiempo.

Aunque encontramos el texto fundamental al inicio de Confesiones, la noción de "inquietud" vertebra la mayoría de los análisis que Agustín realiza entorno a la existencia y la relación del hombre con el mundo a partir de los escritos del año 400 principalmente. La nota doble de la inquietud y el deseo como calificadores a priori de la naturaleza humana no comparecen de manera clara o explícita en los primeros textos de Casiciaco. Ese tono filosófico comienza a prefigurarse hacia el final de la década del 390 a partir de libros como las Cuestiones diversas a Simpliciano ${ }^{19} \mathrm{o}$ La doctrina cristiana ${ }^{20}$ y fue expandiéndose y cobrando importancia a partir de las disputas donatistas y pelagianas. Si bien la inquietud y el deseo aparecen como tono fundamental de la antropología agustiniana, sobre en todo Confesiones debido a la rareza de su género, hay obras de alta envergadura que pueden leerse bajo esa óptica, como los Tratados sobre el Evangelio de san Juan, las Enarraciones so bre los Salmos, los diversos comentarios al Génesis y las obras más típicas de la madurez como la monumental disputa contra Juliano, el texto sobre el cuidado de los muertos, los textos sobre la sexualidad y el matrimonio y, por supuesto, La ciudad de Dios, en especial los libros posteriores al XI, así como muchos otros textos de menor peso pertenecientes al último período de la vida del santo.

Desde esta óptica, la inquietud es una estructura intencional cuyo referente o "noema", para comenzar la traducción de Agustín a una cierta tradición contemporánea como la fenomenología, no está nunca dado como fenómeno de manera adecuada. La inquietud es un modo de relación del hombre con el mundo que dice una estructura antropológica fundamental caracterizada por la intentio, tal como es descrita por el propio Agustín en Confesiones XI o De Trinitate IX y $X$. Esta intentio, sin embargo, no encuentra cumplimiento en objeto mundano ninguno, pues sólo puede verse satisfecha por el encuentro con aquello que Agustín llama "Dios" y que, por su propia naturaleza, no puede comparecer bajo las coordenadas del mundo ${ }^{21}$. Sobre esta estructura intencional de la vida puede vivirse de muchas maneras, incluso

12. Marion 1986, 1997.

13. Henry 2000, 2002, 2004.

14. 14 Chrétien 2000, 2002, 2007.

15. Lacoste 1990, 1994, 2008.

16. Janicaud 1991.

17. Henry 2000, pp. 158 ss.

18. 18 conf. $I, 1,1$

19. Simpl. I, 22.

20. doctr. chr. $1,4-14$

21. Io. eu. tr. CI, 5; CII, 1-6; ep. lo. tr. III, 11-13; VII, 9-10; f. inuis. V, 8. 
no necesariamente bajo la forma de la vida de un creyente, pero en todos los casos la vida humana toma la forma de la persecución de una realidad absoluta ${ }^{22}$. Esta direccionalidad o intencionalidad puede verse permanentemente insatisfecha, frustrada, negada o incluso afirmada, pero en todos los casos permanecerá como una tensión sobre la que se construye el desenlace fáctico de la vida.

En efecto: somos cuerpo. Estamos siempre localizados en un lugar y en un momento. Nuestra existencia está marcada por una topología, por unas circunstancias y unas coordenadas a las que no puedo ser sordo y que no puedo obviar si quiero describir quién soy ${ }^{23}$. En esas condiciones topológicas mi vida está transida desde el inicio por un hiato: aquél que se abre entre lo que soy de hecho y lo que quiero llegar a ser, pero también por el hueco que hay entre lo que vivo en mi interioridad y lo que de ello expreso ${ }^{24}$. Por más que hable, por más que actúe, siempre queda un residuo dentro mío que no logro externar del todo. Mi cuerpo es menos grande que mi interioridad y mi lenguaje es precario, al comparársele con lo que vivo y experimento en mi conciencia. Este doble desfase, esta doble desarticulación entre lo que soy, lo que pienso y lo que quiero, así como entre lo que vivo en mi interioridad y lo que de ello externo, es la condición nativa sobre la que se monta el deseo humano y toda actividad del hombre: quiero ser, pero no siempre sé qué es aquello que quiero ni puedo realizarlo bien del todo. Esta inadecuación es primordialmente objetiva, es un factum que me ha sido dado sin haber querido; de eso va fundamentalmente la vida, de ir poco a poco desbrozando y articulando el deseo de lo que quiero e intentando conseguir su objeto ${ }^{25}$. Cuando esta situación fundamental de inadecuación objetiva es experimentada desde mi interior, es decir, cuando me doy cuenta de que verdaderamente mi vida depende mí y de que cabe la posibilidad del éxito pero también la del fracaso, entonces experimento una inquietud fundamental ${ }^{26}$.

La idea agustiniana de "inquietud" permite decir esta desarticulación, pues atiende no a una emoción, sentimiento o vivencia concreta, sino a una situación primordial de lo que implica la topología de la vida humana. Sea cual sea el proyecto que emprenda o el deseo que intente saciar, viene otro inmediatamente a suplir al anterior. Por eso la situación es precisamente "inquietud", ausencia de paz y estabilidad, es movimiento originario e intento permanente de felicidad.

A pesar de que el Dios de Agustín no comparezca sino bajo el modo de la fe, el sentido de esa intimidad exhibida puede ser comprendido por la filosofía, que es capaz de explorar el sentido de su alabanza y de la inquietud que en ella comparece. Es cierto que la noción de "Dios" es la noción de un correlato vivencial que está fenomenológicamente velado, pero no es menos cierto que la alabanza que constituye el pasaje citado aparece como un fenómeno comprensible en su sentido. Ella es, en principio, un movimiento existencial de abajamiento, de reconocimiento de la finitud y de la fragilidad humanas, de la aceptación de que la vida depende de una alteridad. Claro que el contenido de la alabanza que hace Agustín: "grande eres y laudable sobremanera..." modificará su carácter, pero su estructura implica el reconocimiento de una otredad superior a quien alaba en más de un sentido. El contraste, en este caso, que hay entre lo alabado y el alabante hace comparecer para Agustín la inquietud del corazón humano como su característica más definitoria. Así ha definido Jean-Yves Lacoste esta situación eminentemente paradójica: "la inquietud, según su formulación clásica en el «incipit» de las Confesiones de Agustín, es esa nota de la humanidad del hombre que lo sustrae a toda satisfacción cuya medida la den el mundo y la tierra, y lo ordena hacia la satisfacción escatológica que, por simple definición, sólo lo Absoluto promete. El hombre inquieto puede así aburrirse del mundo y de la tierra, puede soñar con un más allá del mundo y de la tierra." 27 Siendo parte del mundo, el ser humano se sustrae a cualquier satisfacción mundana.

La situación fundamental ${ }^{28}$ de la inquietud provisionaliza todo bien propuesto por la topología, todo bien inscrito en las coordenadas espacio-temporales del mundo e instala al ser humano en una situación de precariedad. No solamente porque la inquietud es una situación que enfrenta al hombre con aquello que pueda satisfacerle y exhibe de bruces la insuficiencia de lo mundano, sino porque ella viene motivada también por la incapacidad fundamental del hombre de expresar con hondura y precisión aquello que él mismo es. Si el lenguaje puede funcionar como un medio para exteriorizar lo que ocurre en la vida interior, hay que admitir que nunca dejamos de aprender a hablar. No terminamos nunca de crecer en lenguaje y en palabras, siempre podemos decir y expresar mejor la vida. Lo mismo ocurre con la acción, que busca hacer realidad lo que solamente estaba en el mundo de la idea y del concepto o del impulso inefable, por eso tampoco terminamos nunca de aprender a actuar: en la ecuación de la expresión hay siempre un residuo de interioridad que queda sin ser expresado del todo. Nuestra inquietud fundamental tiene que ver con esa inefabilidad primordial de nuestra vida que está siempre a la espera de ser dicha, formulada, comprendida, comunicada y experimentada en plenitud.

La inquietud no es desasosiego ni desesperación, aunque puede conducir a ellas. La inquietud no es una emoción concreta ni una vivencia específica. El desasosiego, la desesperación o la ansiedad son formas de vivir la inquietud, lo mismo que la paciencia, la esperanza, el deseo y el amor. La inquietud no predetermina nada ni predispone a nada, excepto al movimiento y a la búsqueda de la paz, y su medida no la da nada del mundo. Por ella buscamos la felicidad, que es incluso su cuestión central, aunque todo el mundo pueda hacerlo en un lugar distinto.

La inquietud es el primer acicate, la primera flecha de la ballesta de la vida que mueve al hombre a buscar la felicidad. Ella toma la forma concreta de deseos determinados, que se vuelven amores y proyectos, que a su vez pueden acercar el ideal de la paz o acrecentar la inquietud. Los deseos que surgen desde el fondo del alma cobran así una importancia muy grande pues, ni podemos simplemente acallarlos y hacer oídos sordos a su exigencia, ni tampoco podemos obedecerlos

22. Lacoste 1990, pp. 96-140, 1994, pp. 79-105

23. Lacoste 1994, p. 15 ,

24. mag. XIII, 41-44, s. $373,374,375$.

25. s. $346,346 A, 346 B, 346 C$

26. conf. I, 1, 1; Io. eu. tr. $L X, L X X I I I$.

27. Lacoste 1994, p. 35.

28. La expresión "situación fundamental" para decir esta nota de la existencia humana es original de M. García-Baró, 2006. 
y darles cauce sin límite alguno.

Así lo ha dicho Hannah Arendt: "el hombre tiene la opción de no querer encontrarse en casa en el mundo y de mantenerse en actitud de remisión constante al Creador" ${ }^{29}$, y si tiene esa opción es porque puede aún mantener la espera -o esperanza- en bienes o estados mucho mejores y mayores y más valiosos que lo que el mundo tal cual y como es puede ofrecerle. La inquietud se transforma así, poco a poco, en deseo, en appetitus que va buscando y va intentando, a lo largo de la existencia, ser saciado. Toda acción humana es, de este modo -y aunque sea veladamente-, un intento de comprobación de la hipótesis sobre qué pueda ser la beata vita, la maravilla que pueda saciar los más profundos anhelos del corazón humano ${ }^{30}$. Así, incluso, es como puede interpretarse toda acción humana y toda empresa o proyecto que puedan emprender los hombres:

todas las funciones de la acción tienen como meta ese fruto de la contemplación -comenta Agustín en el tratado Cl sobre el Evangelio de san Juan-, pues es el único libre porque se desea por sí mismo y no por mor de otra cosa [quia propter se appetitur, et non referetur ad aliud]. A este fin sirve la acción. En efecto, cualquier cosa que se hace bien, lo tiene como meta, pues se hace en razón de este fin y no en razón de otra cosa, sino en razón de él mismo. Uno se atiene a él y lo tiene. Ahí, pues, está el fin que nos basta. Por tanto, será eterno, pues no nos basta un fin, sino ese que no tiene fin alguno. ${ }^{31}$

El deseo se exhibe, así, como exasperante cuando tomamos por excelentes las cosas que son solamente mejores y como mejores las que son únicamente buenas, y cuando a todas las queremos como si fueran más perfectas de lo que son o, más aún, cuando nos tomamos a nosotros mismos como el bien que queremos, dirigiendo el appetitus no hacia los bienes superiores sino hacia nosotros mismos. De hecho, puede decirse que el deseo de Dios es un deseo cualitativamente distinto que el deseo de los bienes del mundo, aunque fácilmente -ahí está el problema- pueda pensarse que son deseos del mismo talante. Así lo afirma Martín Velasco:

un doble error del hombre pone en peligro la realización adecuada de su ser desde el punto de vista del deseo: confundirlo con los múltiples deseos y pensar que la posesión de los muchos bienes puede acallar su deseo radical; y concebir el deseo radical como un deseo mayor, pero de la misma naturaleza, que puede ser saciado por bienes de la misma naturaleza que los que responden a sus muchos deseos, aunque mayores que todos ellos. ${ }^{32}$

Pero todo indica que este deseo del mundo es siempre signo y puerta de entrada al conocimiento que el hombre puede tener de su propio deseo de lo Absoluto.

\section{LA PRESENCIA DE AGUSTÍN EN LA FILOSOFÍA CONTEMPORÁNEA}

Las dos notas estructurales de la antropología agustiniana que he presentado: la inquietud y el deseo, aparecen bajo varias formas tomando parte en los proyectos estructurales de algunos filósofos contemporáneos que, desde mi punto de vista, encuentran una deuda fundamental con la elaboración de la antropología existencial de san Agustín. El primero de ellos es Maurice Blondel, quizá el agustiniano más fiel, que supo bajo el método de la inmanencia -un método fenomenológico sui generis-, decir la idea de inquietud que encontramos en Confesiones. La obra de Blondel comienza con la disimetría entre ser, pensar y actuar, y desvela en el análisis inmanente de la acción un sentido trascendente y escatológico de ella que se exhibe de manera completamente performativa ${ }^{33}$. Lamentablemente, Maurice Blondel no tuvo discípulos que lo siguieran y que hicieran avanzar sus intuiciones filosóficas tan profundamente fieles a su maestro Agustín, pero es posible decir, sin embargo, que tenemos en Jean-Yves Lacoste a uno de los más significativos exponentes de este nuevo agustinismo de corte blondeliano. Lacoste ha ido construyendo poco a poco una "filosofía de la liturgia" a partir de la aceptación explícita del principio agustiniano de la inquietud. Sus grandiosas obras Note sur le temps y Expérience et Absolu son precisamente el desarrollo en lenguaje fenomenológico de la descripción de la existencia personal en su facticidad mundana que desarrolla san Agustín con lenguaje clásico.

Es en este punto que, por fin, algo debemos decir sobre el pensador alemán del que parte buena parte del lenguaje fenomenológico de Lacoste: Martin Heidegger. Sobre este hombre y su influencia agustiniana se ha escrito mucho, y es evidente, tan solo leer los Sermones y las Cartas del viejo Agustín, que la mismísima noción de Sorge, de "cuidado o cura" ${ }^{34}$, tiene su ancla más fundamental en la agustiniana cura vitae, aunque de manera secularizada. Como lo ha mostrado, por ejemplo, Philippe Cappelle-Dumont ${ }^{35}$, fue la secularización de la lectura de san Pablo y del libro $X$ de las Confesiones, textos que hoy conocemos bajo los nombres de Introducción a la fenomenología de la religión ${ }^{36}$ y Estudios sobre mística medieval ${ }^{37}$, lo que permitió a Heidegger dar con la idea de Sorge como la nota estructural, o el existenciario, más fundamental del Dasein. Si consideramos a la inquietud con la suficiente radicalidad, veremos que una existencia que vive bajo su sino y levanta, por ello, una plegaria al Absoluto, transgrede lo que Heidegger llama 'facticidad', es decir, el condicionamiento total por el horizonte de lo mundano, pues esta inquietud lleva a quien reza a olvidar la muerte o, al menos, a poner entre paréntesis su ser-para-la-muerte. Lo interesante, al menos a juzgar por los textos agustinianos y por el modo como el propio Heidegger lo vio en sus lecciones de 1921, es que el horizonte escatológico por el que se posibilita la transgresión se recibe, si se

29. Arendt 1929, p.93.

30. Cfr. García-Baró, 2005, 2007.

31. Io. eu. tr. Cl, 6 .

32. Velasco 2006, p. 152.

33. Blondel 1893, pp. [VII]15 - [XXV]33.

34. Heidegger 1927, p. 200.

35. Capelle-Dumont 2012, pp. 202-217, 230-238.

36. Heidegger 1995, pp. 113-149

37. Heidegger 1995b, pp. 13-155. 
recibe, siempre bajo las condiciones de lo que es transgredido: el mundo [regio dissimilitudinis ${ }^{38}$ ], o lo que Lacoste llama 'topología', de modo que la vida del que ora es una tensión contra la facticidad condenada a vivirse desde aquello que quiere transgredir. Si en la preocupación me hago cargo de mí mismo y de mi muerte, en la inquietud mi muerte está entendida desde un horizonte allende ella. Si la preocupación la pone el yo sobre sí y hacia el futuro, la inquietud precede al yo y está ahí aún antes de ser constituida por él. La inquietud se da aún antes siquiera de que un yo la constituya como deseo (y menos aún como voluntad, entre otras razones porque su objeto me está prácticamente velado). El appetitus (deseo) originario y primigenio de escatología (de que la historia se vea ya cumplida siempre) no es un acto propio del yo pero está presente en él desde un tiempo inmemorial, por eso el yo está inquieto respecto de algo mucho más grande que sí mismo. La inquietud anhela siempre la última palabra sobre las últimas cosas, es decir, un Absoluto.

Es a partir de aquí que surgió una figura como la de Lacoste, pero también es de ahí de donde han abrevado figuras como Michel Henry y los más contemporáneos Jean-Luc Marion y Jean-Louis Chrétien, y es en este punto en donde quisiera hacer una pequeña digresión sobre la influencia de Agustín en la fenomenología, pues no es una mera casualidad que Husserl citara en al menos dos ocasiones importantes alguna frase de Agustín. Tanto el cierre de las M editaciones cartesianas ${ }^{39}$ como la apertura de la Fenomenología de la conciencia interna del tiempo ${ }^{40}$, llevan dos sendas citas y reflexiones sobre el filósofo africano. En especial la segunda que he mencionado es digna de considerarse, pues la obra sobre el tiempo ha sido verdaderamente central para el desarrollo de la filosofía de Michel Henry y de hermeneutas como Paul Ricœur.

En efecto, el análisis de la conciencia interna del tiempo que publicó Husserl en 1928, pero que comenzó a elaborar desde 23 años antes, marca un hito en los estudiosos filosóficos del tiempo, que habían encontrado muy pocos valientes para adentrarse en ellos y que sólo, quizá, contaban con Aristóteles ${ }^{41}$, Kant ${ }^{42}$, y Bergson ${ }^{43}$, además de Agustín, como antecedentes serios.

Es posible decir que Agustín avanzó dos perspectivas fundamentales al respecto: la objetiva y la íntima. La primera fue desarrollada por él, sobre todo, en los textos más propiamente neplatónicos y más adelante en los comentarios al Génesis. Ahí suele tratarse el tiempo como una dimensión objetiva del mundo, creada, real, existente ${ }^{44}$. Confesiones XI, sin embargo, revela la perspectiva más tradicionalmente considerada por los historiadores de la filosofía, la comprensión del tiempo como distentio animi, como una propiedad íntima del alma, o incluso como el modo de ser de ésta bajo las condiciones del mundo ${ }^{45}$. El último libro sobre el tiempo que conozco y que ha tomado estas ideas en cuenta es el de Claude Romano, El acontecimiento y el tiempo ${ }^{46}$, publicado hace ya 20 años en 1999, un libro algo descuidado respecto del tratamiento que da a los análisis agustinianos sobre el tiempo y que contrasta sobremanera con la agudeza y la finura de su precedente, El acontecimiento y el mundo, publicado tan solo un año antes ${ }^{47}$.

Sostengo que esta manera de comprender el tiempo y el alma es la que subyace, tácitamente y mutatis mutandis, en toda la fundación de la fenomenología husserliana, no solamente por la noción del tiempo que comparece en ella, sino por la mismísima noción de "conciencia". De este modo, toda la tarea de la filosofía del siglo XX realizada en clave fenomenológica, e incluyo aquí a algunos hermeneutas, explícitamente a Paul Ricœur ${ }^{48}$, es deudora de la tradición abierta por Agustín en los análisis de la interioridad humana que realiza de manera expresa en la última parte de Confesiones pero también en una multitud de textos dedicados al análisis de la experiencia que el alma tiene de sí, específicamente en De Trinitate ${ }^{49}$

Un texto referencia para este asunto es el libro que publicó Emmanuel Housset hace 13 años, titulado: La vocación de la persona. La historia del concepto de persona de su nacimiento agustiniano a su redescubrimiento fenomenológico ${ }^{50}$, en el que parte de un análisis histórico del origen teológico de la noción de persona, explica la traducción a la metafísica que Agustín hizo de la misma, y argumenta porqué la noción de "sujeto" y de "conciencia" en clave fenomenológica permiten redescubrir esa noción clásica en una tesitura contemporánea.

Por último, no quiero dejar de hacer explícito otro modo en el que la fenomenología de la religión se ha visto marcada por estas mismas nociones. Comencé mi exposición señalando el modo en el que el pequeño pero tremendo libro de Otto, Lo santo, había sido un texto fundamental para la comprensión general de la fenomenología de la religión. A partir de esa idea, señalé la importancia de detectar la experiencia subjetiva por la cual aquello que él nombra como "lo numinoso" 51 y ahora recientemente Martín Velasco bajo el rótulo de "el Misterio" 52, comparecen ante el ser humano. Esa línea de investigación condujo a la necesidad de hacer explícita la noción de "inquietud" como el modo estructural bajo el cual el ser humano despliega su vida

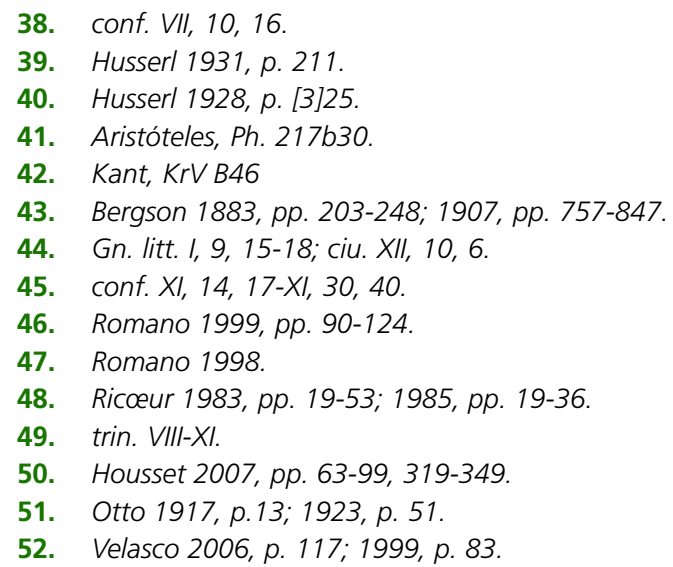


en el mundo. Pero hay que decir que esto es únicamente un lado de la historia, pues si la inquietud es ese movimiento permanente que exhibe la insatisfacción permanente del hombre respecto del mundo, algo también se puede decir respecto aquello que sí lo ha de satisfacer. En ese sentido, la importancia de Agustín para la filosofía de la religión no es menor, pues ha ayudado su pensamiento a calibrar la importancia de distinguir al mundo respecto de la divinidad, un asunto que en Heidegger, por ejemplo, no ocurre sino de manera borrosa. Me refiero, para decirlo explícitamente, a la importantísima distinción entre las nociones de lo "sagrado" y lo "santo", que permiten avizorar las diferencias entre una vía pagana de la existencia religiosa y el monoteísmo ilustrado propiamente dicho.

Ha sido virtud de Miguel García-Baró ${ }^{53}$, un discípulo y colega de Juan Martín Velasco, la de ha acentuar y desarrollar la importancia de la categoría del "acontecimiento" para comprender la religión, y la noción de Dios, como una noción ajena a todo paganismo, sobre todo a partir de aprender a distinguir entre lo "sagrado" y lo "Santo". El filósofo español da cuenta de la importancia de no dar por obvia esta distinción, pues de ella depende la buena resolución de los planteamientos de la metafísica en el mundo contemporáneo. Efectivamente, Agustín no es uno de los filósofos respecto de quienes quepa la acusación de onto-teología y la supuesta violencia inmanente que esto trae consigo. Pues, en efecto, la distinción entre lo sagrado y lo santo, que catapulta a la divinidad hacia coordenadas que no toleran ninguna identificación con la dimensión inmanente de la realidad mundana, está presente en Agustín ya desde el primer momento de su filosofía. No hay en Agustín ninguna traza de confundir a Dios con algún ente del mundo, aunque pueda decirse, en efecto, que desde el punto de vista metafísico, el libro $V$ sobre la Trinidad pueda llamar a sospechas. La realidad es que la noción de Dios en Agustín, como lo han mostrado ya otros como Goulven Madec $^{54}$ o Yves Meesen ${ }^{55}$ es una noción eminentemente relacional, no objetiva y siempre en movimiento, es un Dios que "acontece" en la existencia de manera no programable y liberadora. Es una realidad abierta a la libertad, es promesa y llamada, y no un objeto estático de culto con anquilosamientos de entidad mundana. Para Agustín, Dios no es un objeto más del mundo, sino siempre una realidad relacional que trasciende toda posibilidad de representación y de mundanización, lo que queda mostrado no solamente a partir de la descripción de la inquietud, como una situación humana que no puede encontrar satisfacción nunca con ningún objeto que tenga alguna traza de mundo, sino también explícitamente a partir de la fenomenología de la religión que el propio Agustín elabora en muchos lugares, por ejemplo: "Si Dios subsiste y se le puede llamar con toda propiedad sustancia, existe en Él algo como en sujeto, y entonces no sería ya simple, por no identificarse en Él el ser y sus atributos, como grande, bueno, omnipotente y cualquier otro digno de Dios. No se puede decir que Dios subsiste y es sujeto de su bondad, ni que esta bondad no es sustancia o esencia, o que Dios no es la misma bondad, sino que bondad existe en Él como en un sujeto. Luego es evidente que Dios no es substancia sino en un sentido abusivo" (trin. VII, 5, 10). Estos son los resultados que arroja una investigación sobre la noción de "religión" como separación del paganismo y de la idolatría del mundo en Agustín, según el cuál nada del mundo es Dios ni puede ser comparable con Él. Baste para mostrarlo leer con detenimiento textos como el De vera religione ${ }^{56}$ y abundantes pasajes en De civitate Dei $^{57}$, aunque los pasajes de Agustín sobre el tema abundan en todo lo extenso del corpus ${ }^{58}$.

\section{COMENTARIO CONCLUSIVO}

Para concluir: he intentado sostener la tesis de que la exploración por la vía interior que inauguró Agustín ha crecido de manera fecundísima a lo largo de los siglos, generando una posteridad intelectual cuya importancia no ha podido ser reconocida lo suficiente. El énfasis en las ciencias objetivas que desde la Modernidad tomó a la vida intelectual de Occidente incluyendo a la filosofía misma, ha privilegiado el estudio de la perspectiva naturalista u objetiva, abierta por Aristóteles y proseguida por una muy buena parte de la filosofía. Sin menospreciar por ningún motivo esa noble tradición, he querido acentuar la potencia que la vía de la interioridad y una perspectiva ontológica más bien relacional que sustancialista pueden tener, así como los frutos que pueden rendir para el pensamiento esas líneas de trabajo, específicamente sobre la esencia de lo propiamente humano y sobre la naturaleza del fenómeno religioso desde una perspectiva ilustrada en su justeza misma. La importancia de Agustín, en ese sentido, no puede nunca ser sobrestimada ni exagerada. Es un gigante de la cultura occidental. Su pensamiento ha tenido eco en la filosofía, en la literatura, en la teología y en la política. Soy bien consciente de que he dejado fuera de este trabajo muchos aspectos de importancia suma sobre la presencia de Agustín en la filosofía del siglo XX. Hablé exclusivamente de asuntos propios de la antropología filosófica, de la fenomenología y de la filosofía de la religión, pero queda aún por explicitar la influencia de la visión política de Agustín y sus ecos en la filosofía política contemporánea. Pienso en Giorgio Agamben ${ }^{59}$, en Iván Illich ${ }^{60}$ y en la influencia agustiniana de las exploraciones políticas de Hannah Arendt ${ }^{61} \mathrm{y}$ de Charles Taylor ${ }^{62}$. Del mismo modo, la figura del gigante de Hipona está presente de manera importante en algunos filósofos de la posmodernidad, como Derrida ${ }^{63}$, Lyotard ${ }^{64}$ o el escritor

53. García-Baró 2006, pp. 169-185; 2007, pp. 199-220; 2012, pp. 119-137; 2016, pp. 39-63.

54. Madec 1998, pp. 97-152.

55. Meessen 2011, pp. 29-64.

56. uer. rel. $X V I I I, 35-X X V, 46$.

57. сіи. II-III.

58. c. Sec. 6-26; cura mort. 1,2-6,8; f. inuis. IV, 7; c. Fort. 15; agon. IV, 4-6; por mencionar sólo algunos loci interesantes.

59. Agamben 2008

60. Illich 1993.

61. Arendt 1958.

62. Taylor 1989; 1994; Rosales 2016.

63. Derrida 2007.

64. Lyotard 1998. 
Miklós Szentkuthy ${ }^{65}$. Por último, hay que mencionar la importante tradición italiana del pensamiento agustiniano, representada por Michele Federico Sciacca ${ }^{66}$ y Augusto del Noce ${ }^{67}$, pensadores interesantísimos que no han podido ser tratados en este trabajo, o la filosofía personalista alemana temprana: Przywara ${ }^{68}$, Stein ${ }^{69}$ y Guardini ${ }^{70}$.

En cualquier caso, tengo para mí que una de las contribuciones más importantes en el mundo contemporáneo es justamente la noción de "inquietud", pues ella nos invita al asesinato de todos los ídolos, es el camino de la aniquilación de los tótems del mundo contemporáneo que traen consigo la violencia por afirmarlos, ya desde el punto de vista personal como desde el punto de vista público. La filosofía de la existencia personal que trazó Agustín de Hipona en su contexto helenísitco y romano es actualísima, es una filosofía de la libertad que otorga potencia a las facultades humanas al no idolatrarlas, pues el hombre en Agustín no es nunca autorreferencial, sino que siempre está sostenido por una realidad más grande que él, una realidad buena y bella, que puede ser constatada y experimentada, cuando menos, a contrario, a través de la contemplación del orden de la naturaleza, pero también y de manera mucho más dramática y verdadera a través de los acontecimiento que suceden a la libertad, de las múltiples provocaciones que recibe el corazón del hombre y que resuenan más dentro que la intimidad y de manera más perfecta que todo lo que el hombre pueda pensar.

65. Szentkuthy 2014.

66. Sciacca 1949.

67. Del Noce 1982.

68. Przywara, 1934.

69. Stein, 1937.

70. Guardini, 1939. 


\section{OBRAS DE SAN AGUSTÍN:}

(agon.) El combate cristiano, trad. de L. Cilleruelo. Obras completas XII. Madrid: BAC.

- (c. Fort.) Actas del debate con Fortunato, trad. de L. Vizcaíno. Obras completas XXX. Madrid: BAC.

- (c. Sec.) Respuesta a Secundino, trad. de L. Vizcaíno. Obras completas XXX. Madrid: BAC.

- (ciu.) La ciudad de Dios, trad. de S. Santamaría y M. Fuentes. Obras completas XVI-XVI. Madrid: BAC.

- (conf.) Confesiones, trad. de A. Custodio. Obras completas II. Madrid: BAC.

- (cura mort.) La piedad con los difuntos, trad. de T. C. Madrid. Obras completas XL. Madrid: BAC.

- (doctr. chr.) La doctrina cristiana, trad. de B. Martín. Obras completas XV. Madrid: BAC, 1957. en. Ps., Enarraciones sobre los Salmos, trad. de B. Martín. Obras completas XIX-XXII. Madrid: BAC.

- f. inuis., La fe en lo invisible, trad. de H. Rodríguez. Obras completas IV. Madrid: BAC.

- Gn. litt., Comentario literal al Génesis, trad. de B. Martín. Obras completas XV. Madrid: BAC.

- lo. eu. tr., Tratados sobre el Evangelio de san Juan, trad. de J. Anoz. Obras completas XIII-XIV. Madrid: BAC.

- mag., El maestro, trad. de M. Martínez. Obras completas III. Madrid: BAC.

- Simpl., Cuestiones diversas a Simpliciano, trad. V. Capánaga. Obras completas IX. Madrid: BAC. trin., La Trinidad, trad. de L. Arias. Obras completas V. Madrid: BAC, 2006. uera. rel., La verdadera religión, trad. de V. Capánaga. Obras completas IV. Madrid: BAC.

OTRAS REFERENCIAS: WArendt, H. (1929). El concepto de Encuentro, 2009. amor en san Agustín, trad. de A. Serrano de Haro. Madrid: Ediciones

- _ (1958). The Human Condition. Chicago: The University of Chicago Press.

- Aristóteles. Física.

- Agamben, G. (2008). El reino y la gloria, trad. de F. Costa, E. Castro y M. Ruvituso. Buenos Aires: Adriana Hidalgo Editores.

- Bergson, H. (1883). Essai sur les données immédiates de la conscience. Euvres I. Paris: Le livre de Poche, 2015.

- _ _ (1907). L'évolution créatrice. CEuvres I. Paris: Le livre de Poche, 2015.

- Blondel, M. (1893) L'action. Essai d'un critique de la vie et diune science de la pratique. CEuvres

- I. Paris: Presses Universitaires de France, 1995.

- Bochet, I. (1982) Saint Augustin et le désir de Dieu. Paris: Institut d'études augustiniennes.

• __ (2009) “Le statut de l'image dans la pensée augustinienne”. Archives de Philosophie, 72 (2), 249-269.

- Brown, P. (2000). Augustine of Hippo. A Biography. Berkeley \& Los Angeles: University of

- California Press.

- Cappelle-Dumont, P. (2012). Filosofía y teología en el pensamiento de Martin Heidegger. trad. de P. Corona. México: Fondo de Cultura Económica.

- Chrétien, J. L. (2000). Le regard de l'amour. Paris: Desclée de Brouwer.

- _ (2002). Saint Augustin et les actes de parole. Paris: Presses Unviersitaires de France.

- _ (2007). La joie spacieuse. Essai sur la dilatation. Paris: Les Éditons de Minuit. 
- De Simone, G. (2013) “'́intériorité via ad Deum dans la phénoménologie du christianisme de Michel Henry". pp.593-603.

- Del Noce, A. (1982). L'interpretazione transpolitica della storia contemporanea. Napoli: Guida- Derrida, J. (2007). Des Confessions. Paris: Stock.

- Eliade, M. (1957). Lo sagrado y lo profano, trad. de L. Gil. Barcelona: Ediciones Paidós, 1998.

- Falque, E. (2008). Dieu, la chair, et l'autre. D'Irénée a Duns Scot. Paris: Presses Universitaires de France.

- García-Baró, M. (2005). Filosofía socrática. Salamanca: Ediciones Sígueme.

- _ (2006). Del dolor, la verdad y el bien. Salamanca: Ediciones Sígueme.

- _ _ (2007). De estética y mística. Salamanca: Ediciones Sígueme.

- (2012). Elementos de antropología filosófica. Morelia: Jitanjáfora.

- _ (2016). La filosofía como sábado. Madrid: PPC.

- Gilson, E. (1929). Introduction è l'étude de Saint Augustin. Paris: Librairie Philosophique J. Vrin.

- Giraud, V. (2013) Augustin, les signes et la manifestation. Paris: Presses Universitaires de France.

- Guardini, R. (1939). Mundo y persona. Ensayos para una teoría cristiana del hombre. Madrid: Ediciones Encuentro.

- Henry, M. (2000). Encarnación. Una filosofía de la carne, trad. de J. Teira, G. Fernández y R. Ranz. Salamanca: Ediciones Sígueme, 2001.

(2002). Paroles du Christ. Paris: Éditions du Seuil. (2004) Phénoménologie de la vie. Tome IV. Paris: Presses Universitaires de France.

- Heidegger, M. (1927) El ser y el tiempo, trad. de J. Gaos. México: Fondo de Cultura Económica.

Siruela.

(1995). Introducción a la fenomenología de la religión, trad. de J. Uscatescu. México D. F./Madrid: Fondo de Cultura Económica/

(1995b). Estudios sobre mística medieval, trad. de J. Muñoz. México: Fondo de Cultura Económica.

- Housset, E. (2007). La vocation de la personne. L'histoire du concept de personne de sa naissance augustinienne à sa redécouverte phénoménologique. Paris: Presses Universitaires de France.

- Husserl, E. (1928). Lecciones de fenomenología de la conciencia interna del tiempo, trad. A. Serrano de Haro. Madrid: Editorial Trotta, 2002.

- _ (1931). M editaciones cartesianas, trad. J. Gaos y M. García-Baró. México: Fondo de Cultura Económica.

- Illich, Iván. (1993). En el viñedo del texto. Etiología de la lectura: comentario al Didascalicón de Hugo de san Víctor, trad. de M. I. González. México: Fondo de Cultura Económica, 2004. Janicaud, D. (1991). Le tournant théologique de la phénoménologie française. Combas: L’Éclat Kant, I. (1781). Crítica de la razón pura, trad. de P. Ribas. Madrid: Alfaguara.

- Lacoste, J . - Y. (1990). Note sur le temps. Essais sur les raisons de la mémoire et de l'espérance. Paris: Presses Universitaires de France.

- (1994). Experiencia yAbsoluto. Cuestiones disputadas sobre la humanidad del hombre, trad. de Tania Checchi. Salamanca: Ediciones Sígueme, 2010

- _ (2008). La phénoménalité de Dieu: neuf études. Paris: Les Éditions du cerf.

- Lyotard, J.-F. (1998). La Confession d’Augustin. Paris: Galilée.

- Madec, G. (1998). Le Dieu d’Augustin. Paris: Les Éditions du Cerf.

- Marion, J. L. (1986). Prolégomènes à la charité. Paris: Éditions de la Différence. 
-

(1997). Étant donné. Essai d'une phénoménologie. de la donation. Paris: Presses Universitaires de France.

(2008) Au lieu de soi. L'approche de saint Augustine. Paris: Presses Universitaires de France.

- Meessen, Y. (2011). L'être et le bien. Relecture phénoménologique. Paris: Les Éditions du Cerf.

- Otto, R. (1917). Lo Santo. Lo racional y lo irracional en la idea de Dios, trad. de F. Vela. Madrid: Alianza Editorial.

(1923). Ensayos sobre lo numinoso, trad. M. Abella. Madrid: Editorial Trotta.

- Petit, J.-F. (2015). Saint Augustin, notre contemporain. Lectures au XXe siècle. Paris: Bayard.

- Przywara, E. (1934). Augustinus: die Gestalt als Gefüge. Jakob Hegner.

- Romano, C. (1998). El acontecimiento y el mundo, trad. de F. Rampérez. Salamanca: Ediciones Sígueme, 2012.

• _ (1999). L'événement et le temps. Paris: Presses Universitaires de France.

- Rosales, D. I. (2016) "El surgimiento de un yo. Las raíces agustinianas de las nociones de "identidad" y "autenticidad" en Charles Taylor". Revista de filosofía, 140, 87-110.

- Sciacca, M. F. (1949). S. Agostino. Brescia: Morcelliana.

- Scheler, M. (1921) De lo eterno en el hombre, trad. de J. Marías y J. Olmo. Madrid: Ediciones Encuentro, 2007.

- Schleiermacher, F. (1830). La fe cristiana, trad. de C. Ruiz-Garrido. Salamanca: Ediciones Sígueme, 2013.

- Stein, E. (1937). Ser finito y ser eterno. Ensayo de una ascención al sentido del ser. México: Fondo de Cultura Económica.

- Szentkuthy, M. (2014). Leyendo a Agustín, trad. de A. Kovacsis. Barcelona: Ediciones del subsuelo.

- Taylor, C. (1989). Sources of the Self. The Making of M odern Identity. Cambridge: Harvard University Press.

$\bullet$ (1994) La ética de la autenticidad, trad. de P. Carbajosa (trad.), Barcelona: Paidós. Velasco, J. M. (1999) El fenómeno místico. Madrid: Editorial Trotta.

- _ـ (2006) Introducción a la fenomenología de la religión. Madrid: Editorial Trotta.

- Williams, R. (2016). On Augustine. London: Bloomsbury. 